\title{
ISCTR Updates
}

Published online: 5 August 2021

(C) Springer Science+Business Media, LLC, part of Springer Nature 2021

The current educational curricula in universities lack the education on how to develop a medical product. Our medical school emphasizes on the diagnosis and treatment of diseases and how to use a medical product, but rarely teaches how to develop products. As a result, the current innovation ecosystem is inefficient; therefore, we currently spend approximately 15 years and 1 to 2 billion dollars to develop medical products, whether diagnostics or therapeutics. It is critical that we have a robust system in place (translational pathways for medical product) that explains and teaches step-by-step the development of medical products. With the current system, 1 out of 3,000 ideas and less than $10 \%$ of startup companies will succeed. Translational pathways for medical products is a complex process that requires a profound understanding of the unmet clinical need, the methods and endpoints for preclinical and clinical evaluation, intellectual property, business planning, regulatory and reimbursement strategies, practice guideline requirements, and the adoption of new technology.

The International Society for Cardiovascular Translational Research (ISCTR) has collaborated with over 100 experts in medical product development and assembled online courses and eBook on the Translational Pathways for Medical and Cardiovascular Devices. Several universities in the USA have adopted this educational program to their graduate and post-graduate degrees, and we hope many other universities and fellowship programs will follow.

We anticipate the future use of artificial intelligence will save time for physicians, enabling them to participate in product development and innovation, in addition to their standard education.
Expanding our education on how to develop a product (translational pathways for medical product), in addition on how and where to use a product, will expedite scientific discovery to patients, saving lives and decreasing costs.

https://www.isctr.org/

Translational Pathways for Cardiovascular Devices Translational Pathway for Medical Devices eBook - Translational Pathways for Cardiovascular Devices

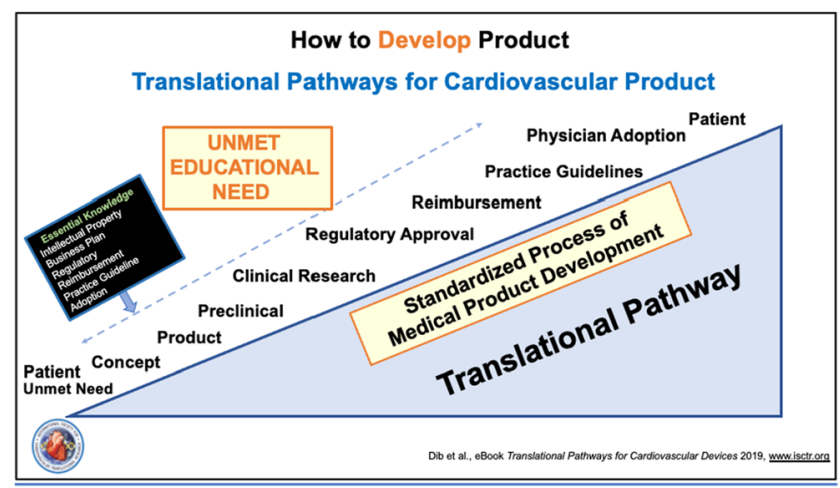

Publisher's Note Springer Nature remains neutral with regard to jurisdictional claims in published maps and institutional affiliations. 